\title{
Understanding Knowledge Flow Dynamics during the Pre-implementation Phase of an Enterprise Resource Planning Project
}

\author{
Lina Lo \\ Nova Southeastern University \\ lina_lo@ymail.com
}

\begin{abstract}
Knowledge flows unevenly throughout an organization and the problem is that the fundamental dynamics of these flows are still not well characterized in theoretical and computational models. This study built on existing work-knowledge-flow theory, need knowledge generation, and the critical success factors for enterprise resource planning implementation-to examine the multidimensional knowledge-flow phenomenon in context, using the case study methodology to collect three sources of evidenceproject-related documentation, internal archival records, and open-ended interviews - to address the research question: How can need knowledge and its flow across different stakeholders in an organization be explained using a multidimensional knowledgeflow model?
\end{abstract}

\section{Introduction}

Knowledge is a source of organizational competitive advantage but knowledge flows unevenly throughout an organization [17], [18], [20], [21], [26]. Nissen defined knowledge flow as the dynamic movement of knowledge between individuals, or organizations, or points in space, or time. Inefficient knowledge flow hinders an organization's ability to realize its potential [20]. Despite more than 2 decades of knowledge-management (KM) practice to leverage knowledge for an organization's competitive advantage, the current state of KM remains ineffective and uninformed across organizations and sectors [20].

Uneven knowledge flows are particularly pronounced in complex enterprises and initiatives, as noted by Pourzolfaghar et al., who studied knowledge flows between two types of architectural experts during the design phase of a building project [26]. Enterprise resource planning (ERP) is a packaged integrated business process-oriented software information system that enables an enterprise to manage the efficient and effective use of its resources
[14]. ERP systems, as applied in the public sector, are often limited to the budget and treasury components of public financial operations and are referenced as financial-management information systems (FMIS) that enable governments "to plan, execute, and monitor the budget by assisting in the prioritization, execution, and reporting of expenditures as well as the custodianship and reporting of revenues" [2, p. 1]. ERP implementations are complex and costly endeavors. These are lengthy initiatives that can take on average 23 months to complete in the private sector with some pre-implementation lead time for the selection of vendors and implementers [27]. ERP implementations generate tremendous amounts and channels of knowledge flow.

KM has long been used to enhance ERP implementation [11], [13], [23] and to explain some of the difficulties in realizing ERP projects and benefits [3], [6], [24], [28], [29]. Nour and Mouakket proposed a framework of critical success factors (CSFs) for ERP implementation in three dimensions: six fundamental stakeholders (end users, top management, information-systems department, project team, organization, and vendor), three major phases of an ERP project life cycle (pre-implementation, main implementation, and post-implementation), and five different roles each stakeholder may play during each ERP-implementation phase (consultation, participation, fulfillment, authorization, and support) [22]. Some researchers stressed that the efficacy of the various knowledge flows hinged on contextual factors [2], [20].

International financial institutions (IFIs) such as the European Investment Bank, The World Bank, and Asian Development Bank provide financing and technical advisory support to developing countries. One of these initiatives, referred to as the Reforming the Public Financial Management Project or REPFMP, was signed between a developing country and one of these IFIs in 2004 with the goal to reform the country's public financial management system with an ERP system as the core of this initiative. It took 11 years for the resulting ERP system to become operational in 
2015. REPFMP is the first ERP implementation in this country aiming to enhance government efficiency and effectiveness in the comprehensive management of public resources. The REPFMP initiative, with its multitude of stakeholders and corresponding implementation complexities, presents a rich environment for better understanding knowledge-flow dynamics, and enables stakeholders "to translate theory into practice and inform practice with theory" [20, p. 235].

\section{Theoretical framework}

\subsection{Literature review}

Knowledge flows unevenly throughout an organization. The problem is that the fundamental dynamics of these flows are still not well characterized in theoretical and computational models [9], [10], [20]. C. Lin et al. noted that the "research approach of dealing with $\mathrm{KM}$ issues often fails to grasp, especially, the issues of knowledge flow" [10, p. 629]. Nissen portrayed the state of KM research as mostly of a descriptive nature and put forth that the next generation of $\mathrm{KM}$ research should move toward measurement, explanation, and prediction: "Learning from failure can provide important lessons, but such provision depends critically upon knowing what causes failure (e.g. preconditions) and learning how it can be prevented" [20, p. 236]. Nissen highlighted the importance of identifying and distinguishing "the contextual factors that affect the efficacy of various knowledge flow processes" and encouraged researchers "to immerse themselves in operational organizations in the field and to investigate how people as individuals, in groups, in organizations, and in even larger collectivities know and learn" [20, p. 236].

Some have attempted to build conceptual knowledge-flow theory. C. Lin et al. identified a number of factors or determinants - transfer, source, receiver, and flow context-that affected knowledge flow, and proposed a hybrid model that included a triangulation scheme to illustrate the multidirectional nature of and adaptive interactions among the determinants of knowledge flow [10]. Kim et al. developed a tool based on social-network analysis to trace organizational knowledge paths to identify where and how knowledge flows and stops [9]. Nissen proposed a five-dimensional knowledge-flow model to characterize a particular knowledge and to represent the efficacy in achieving a knowledge-based action [20]. Nissen described knowledge characters in four dimensions: explicitness (explicit versus tacit knowledge), reach (from individual to group to organization to inter-organization), lifecycle (activities associated with knowledge flows such as creation, sharing, or application), and flow time (in minutes, days, or years), and denoted efficacy of a knowledge-based action by the knowledge-power dimension [20]. Real-life case applications can further strengthen this five-dimensional model formulation.

Pourzolfaghar et al. developed a technique to capture required (or need) knowledge of two different types of experts (or stakeholders) during the architectural conceptual-design phase of a greenbuilding project to improve knowledge flow among these two different sets of stakeholders based on an earlier four-dimensional knowledge-flow theoretical framework proposed by Nissen [26], [17], [19]. Pourzolfaghar et al. found that knowledge flows along the critical paths of workflows that contribute positively to organizational performance, as posited by Nissen [20], [19]. Pourzolfaghar et al. concluded that "knowledge flows should be planned and managed like workflows" [26, p. 75]. Kaiser, Fordinal, and Kragulj furthered the concept of required or need knowledge, independent of the work by Pourzolfaghar et al., and built a theoretical framework to capture (create and discover) need (or required) knowledge in an organization for the generation of innovative products and services [7]. Kaiser et al. integrated the theory of needs into the theory of knowledge-based organizations. The premise was that needs are "requirements to be met for the individual's wellbeing and the organization's sustainable existence" [7, p. 3501]. Kaiser et al. showed that their model was successful in discovering and generating need knowledge in large organizations in a short time frame. Pourzolfaghar et al. and Kaiser et al. reinforced Jennex's description of $\mathrm{KM}$ as "getting the right knowledge to the right people at the right time" [5, p. 52]. It follows that it is more efficient for an organization to focus on need knowledge and move that through the knowledge flow for the relevant stakeholders.

This study attempted to extend Nissen's fivedimensional knowledge-flow model [20] as the theoretical framework to explain the flow of need knowledge described by Pourzolfaghar et al. [26] and Kaiser et al. [7] across Nour and Mouakket's stakeholder groups of an ERP project [22]. Hanisch, Lindner, Mueller, and Wald linked knowledge to project life-cycle stating that different types of knowledge were needed during the different stages of a project life-cycle [4] and therefore connected Kaiser et al's need knowledge and Nour and Mouakket's CSF framework (see Figure 1).

The REPFMP initiative provided fertile ground for this study of multidimensional knowledge-flow 
phenomena. REPFMP took 6 years from conception to the beginning of ERP-system implementation, with 4.5 years spent on procurement, resulting in a total project life of well over a decade. Although the lifetime of REPFMP is not an anomaly among the 87 implementations studied by Dener et al. [2], REPFMP took longer than the average time to gain traction. Dener et al. noted that effective FMIS (ERP) design and implementation required contextual and countryspecific solutions, echoing Nissen's assertion of a "contextual factors" requirement in knowledge-flow processes [20].

Poon and $\mathrm{Yu}$ considered procurement an important pre-implementation component of ERP adoption and studied practices in Hong Kong and Australia [25]. Negi and Bansal cited that the two most crucial and expensive knowledge phases in a successful ERP implementation lifecycle were requirements engineering and configuration [15]. These are the pre-implementation stages of an ERP implementation, and the pre-implementation phase is a pivotal moment in an ERP project [1], [2]. This study concentrated on the pre-implementation phase of an ERP-implementation lifecycle. In sum, the research was an explanatory single-case study, as described in Yin [30], to understand the phenomenon of knowledge-flow dynamics across all different stakeholder groups over the pre-implementation period of a real-life ERP implementation.

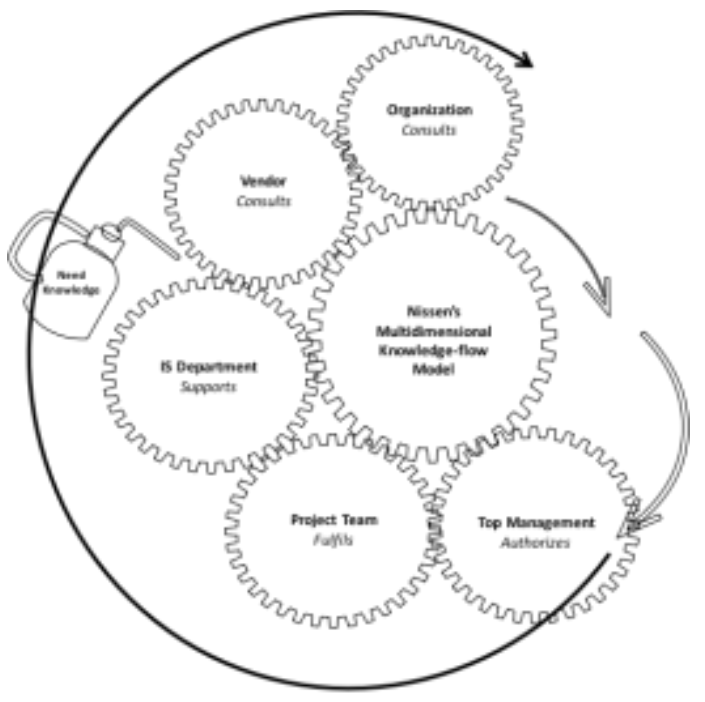

Figure 1: Framework linking data to theoretical propositions

\subsection{Research question}

Pourzolfaghar et al. [26] used Nissen's multidimensional knowledge-flow model [19] as the background theory for their study of need knowledge and its movement between experts to avoid rework due to ineffective KM. Pourzolfaghar et al. extended an activity-based architectural design framework developed by Macmillan, Steele, Austin, Kirby, and Spence [12], merging the theory of knowledge flow with the theory of architectural design. Their work further demonstrated the linkages between knowledge flow and workflows and the multidimensionality of knowledge flow in high-performing organizations. However, there are usually multiple stakeholders participating in a complex project such as the building project described by Pourzolfaghar et al., but they focused on explicating only mechanical and electrical need knowledge and the related flows among mechanical and electrical engineers during the architectural conceptual-design phase of a greenbuilding project in Malaysia.

Kaiser et al. focused on needs and knowledge about needs in organizations and developed a framework for the creation and discovery of need knowledge grounded in abductive reasoning, which is a process that "relies on observations to stimulate possible hypotheses" with "an appeal to instinct" [7, p. 3501]. Kaiser et al. then applied the framework to a large project in Austria to create a catalog of needs for Austrian bakers, who role-played in the study as four different sets of stakeholders: customers, owners or chiefs of bakeries, employees of bakeries, and the Austrian Federal Economic Chamber, the institution that initiated the project. Contributions of the Kaiser et al. study are twofold: (a) integrating the theory of needs into the theory of knowledge-based firms, and (b) using abductive reasoning in the generation of need knowledge. However, they applied the framework developed and described in the study to only one case and at a snapshot moment during a workshop setting.

The Kaiser et al. [7] and Pourzolfaghar et al. [26] studies presented a new process of need-knowledge explication through innovative merging of disciplines with limited empirical work to validate the generalizability of the approaches across organizations and industries. Both groups of researchers focused on tacit knowledge and only hinted at the multidimensionality of knowledge-flow dynamics in organizations. Both used instances outside the realms of information systems, the traditional domain of KM. Taken together, along with Nissen's five-dimensional knowledge-flow model [20] and Nour and Mouakket's ERP CSF classification framework [22], both with limited real-life applications, quite a blank canvas emerged for further elaboration, especially in information-systems research. In this context, the main research gap is the lack of empirical work to 
explain the multidimensional knowledge-flow phenomena in context.

The goal of the study was to validate and extend Nissen's five-dimensional model using a real-life ERP initiative to examine the uneven flow of knowledge through an organization. The study builds on existing frameworks on need-knowledge generation [7], [26], knowledge-flow theory [20], and the ERP CSF classification structure [22] to explain the multidimensional knowledge-flow phenomena in context, using the pre-implementation phase of the REPFMP as a real-life immersion case for knowledgeflow theory building. Validation of Nissen's model [20] was premised on explaining the real-life knowledge flows successfully using Nissen's model. Accordingly, the overall research question to be addressed is: How can need knowledge and its flow across different stakeholders in an organization be explained using a multidimensional knowledge-flow model?

\section{Methodology}

The research was an explanatory single-case study as described in Yin [30] to understand the phenomenon of knowledge-flow dynamics across different stakeholder groups over a period of time in a real-life ERP implementation. The case-study strategy explained why knowledge flows differently across different stakeholders (a contemporary phenomenon) in the context of the REPFMP (a real-life context) by using Nissen's multidimensional knowledge-flow model [20] (a priori theoretical proposition) to generalize how knowledge flows in an organization. For this study case, and following Yin [30], the five research design components were as follows:

1. Research question: How can need knowledge and its flow across different stakeholders in an organization over time be explained using a multidimensional knowledge-flow model?

2. Research proposition: First, the study validated Nissen's proposed five-dimensional knowledgeflow model [20], which has limited empirical work, by considering the multidimensional aspects of knowledge flow in a real-life ERP project. Second, the research adopted five of the six stakeholder groups defined by Nour and Mouakket [22], thereby expanding on Pourzolfaghar et al.'s work with only two stakeholder groups [26]. Third, the proposed study will be longitudinal to cover the multiyear (2004-2009) pre-implementation phase of an ERP initiative, departing from the work of Pourzolfaghar et al. [26] and Kaiser et al. [7], who considered relatively shorter time horizons.
3. Unit of analysis: The unit of analysis was a team of individuals representing the five stakeholder groups-top management, information systems department, project team, organization, and vendor-involved in the pre-implementation phase of FMIS implementation under the REPFMP initiative.

4. Linking data to the proposition: This study used three sources of data-project-related documentation, archival records, and interviews - to capture uneven flow of need knowledge through an organization. These different sources of evidence facilitated triangulation of the collected data. Data analysis relied on linking data on flows of need knowledge across the five different stakeholders through an organization to the proposition that need knowledge flows can be explained by Nissen's multidimensional knowledge-flow model [20].

5. Criteria for interpreting data: The data-analysis strategy adopted for the study followed the theoretical propositions espoused in the five dimensions in Nissen's multidimensional knowledge-flow model [20], the concept of need knowledge advocated in Kaiser et al. [7] and Pourzolfaghar et al. [26], and the three criticalsuccess-factor dimensions in Nour and Mouakket's ERP successful-implementation framework [22]. These theoretical propositions together became the criteria to guide the dataanalysis process to explain the multidimensionality and unevenness of need knowledge flows across five stakeholder groups during the pre-implementation phase of an ERP project.

\subsection{The case}

The IFI-financed REPFMP was the studied case. The core goal of REPFMP was to implement an ERP information system to support the finance ministry of the country's public financial-management processes that included budget planning, execution, and reporting. These budget planning and treasury information systems are generally referred to as FMIS in the IFI and the broader development aid communities. REPFMP was to be the first FMIS implementation for the central government to enhance efficiency, governance, integrity, and transparency of management of public resources.

One of the IFIs agreed to finance the REPFMP in 2003, and the US\$60 million loan agreement was signed in December 2004. The core, almost $90 \%$ of the entire loan, was the implementation of an ERP information system specifically to manage budget 
planning, execution, and reporting. The REPFMP spanned 12 years starting in 2003 when the initial concept of the project took root. It officially closed in December 2015 with the ERP system officially launched in April 2015.

Based on the experiences of 87 World Bank FMIS implementations over 25 years, 55 completed and 32 ongoing projects, Dener et al. [2] found that total duration of completed projects was 7.9 years on average, ranging from 3.6 years in Afghanistan to 13.4 years in Malawi. Duration of the preparation (preloan signing) phase of the 87 implementations averaged 16 months, the effectiveness period (from loan signing to disbursement loan fund) at 6 months, and the procurement of FMIS systems among completed projects took 2.2 years. Taken together, the average duration of pre-implementation, from conception through to the beginning of system implementation of World Bank-financed FMIS projects took about 4 years. The REPFMP took 6 years, with 4.5 years spent on procurement.

\subsection{Data collection}

The case study utilized three sources of evidence: project-related documentation (semiannual progress reports, a midterm evaluation, and monitoring mission reports), internal archival records (e-mails, formal correspondence, legal documents, and minutes of meetings), and open-ended interviews. Before the interview part of the data-collection process, the researcher collected and reviewed project-related documentation (obtained through project team members), and screened the internal archival records filed online in the IFI's REPFMP project portal covering the period from December 2004 to July 2009. The researcher assembled all ERP procurementrelated items from the project-related documentation and archival records to build a chronology of events that delayed the procurement process and those that eventually led toward contract signing in July 2009. The actual chronology of 4.5 years of empirical events occurred during the ERP procurement period was then benchmarked against the planned chronology scheduled to take only 14 months.

Once data from all three sources of evidence were collected, the logic model data-analysis technique was used for explanation building. This logic-model framework was used as the preliminary analytic technique to tie together the chronology of events ("what happened") and initial explanatory propositions ("why it happened"). The logic model data-analysis technique was appropriate at this point as the goal was to match empirically observed events to theoretically predicted events [30].

\section{Results}

\subsection{The data}

The first source of evidence-project-related documents - comprised a total of eight governmentproduced semi-annual reports, including the mid-term review and seven monitoring mission reports by the IFI project team covering the entire studied period. The second source of evidence was the internal archival records deposited in the IFI's internal project portal. There were 20 entries displayed on each screen page of the project portal. Each displayed entry contained either e-mail, formal correspondence, legal document, or minutes of meeting. The researcher scanned through 110 screen pages totaling 2,180 entries. These two datasets provided the chronology of key events of "what happened" and when they happened during the studied period. Key themes began to emerge and further contextualized by the third source of evidence collected through interviewing a small pool of 13 key persons, who were at their posts during the studied period, representing the five stakeholder groups relevant to the pre-implementation phase of an ERP project: top management, information-systems department, project team, organization, and vendor. End-user stakeholder group was not included as this group was not involved at this stage for this case study. These interviews, conducted over a 2-month period, were what Yin referred to as elite interviews, given the particular insights they provided would not be possible from groups [30].

For this case study, knowledge is in the procurement domain. Gaining the procurement knowledge would facilitate and accelerate the acquisition of the information system needed to improve the efficiency and effectiveness of the finance ministry's public financial management. The desired knowledge flow for the ministry would inevitably be for the procurement knowledge to flow quickly, directly, and with high power, starting from one individual to 100 , for example, and for all to be equally able to apply the knowledge to complete the procurement process. For an organization to rapidly gaining and applying a new knowledge-completing the knowledge life cycle throughout the organization-would mean that the knowledge more or less stays at the tacit knowledge plane as described by Nissen [20]. Though a highly-desired state for an organization is to have knowledge flow directly, quickly, and powerfully, often there is obstruction along the way as organizations in general lack processes to support direct, quick, and powerful knowledge flow [20]. 
Data collected for this case study indicate that there are three determinants for need knowledge: intrinsic, extrinsic, and catalytic. All three determinants must be present to fulfil the procurement knowledge-flow loop, missing one would result in an incomplete knowledge-flow loop, and each need knowledge determinant resides with different stakeholder group (see Figure 2).

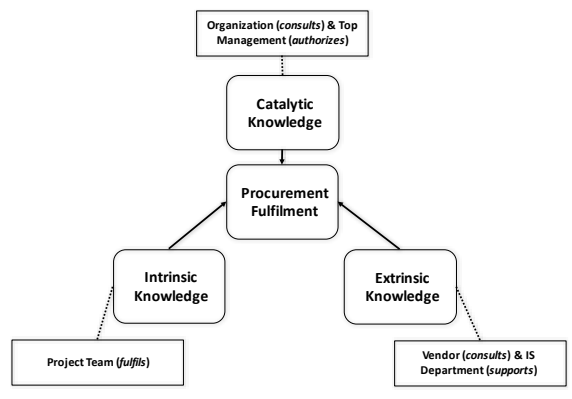

\section{Figure 2: Need knowledge determinants in} knowledge flow

Intrinsic knowledge refers to general procurement knowledge that includes the mechanical process itself (tacit), and the associated written procedures and guidelines (explicit) that direct the process. The project team stakeholder group that executes/fulfils the procurement should possess intrinsic need knowledge. One recurring complain, and documented repeatedly in the government's semi-annual reports during the early period of the project, was "insufficient training on and understanding of the procurement processes."

Extrinsic knowledge in this case refers to the knowledge of the ERP system to be procured. Extrinsic knowledge is needed to assess the technical aspect of the bids submitted. One of the interviewees (Interviewee 8) said that the bidding document was difficult to use, to assess the bidders, and with no experience in ERP procurement, it was difficult to define/understand the requirements. The project team stakeholder group does not necessarily have to attain ERP knowledge, but ERP knowledge is needed to fulfil the procurement process, and therefore individual procurement process calls for a different corresponding extrinsic knowledge. In this case study, extrinsic knowledge was with two stakeholder groups: the vendor represented by the IVV consultancy team and the ministry's information-system department. The latter actually did not have the proficiency of ERP knowledge.

Catalytic knowledge is the authorizing environment to sign off of the procurement results. Without the catalytic knowledge to validate the procurement results, the procurement knowledge-flow loop remains incomplete. Catalytic knowledge enables Nonaka's Ba (Nonaka et al., 2000), or what Kaiser et al. (2014) referred to a "special kind of Ba", a "timespace-nexus" of "shared space", to complete the procurement knowledge-flow loop as evidenced in this case study when a review of the procurement process was ordered by the finance minister to assure procurement compliance prior to progressing to the next stage of the procurement process as documented in the project-related documentation, archival records, and by all interviewees (more in the next subsection). Top management under consultation with the organization stakeholder group possessed the catalytic knowledge.

\subsection{Chronology of events}

The pre-implementation phase of the FMIS under REPFMP was the period from the date the loan was signed between the government of the case study and the IFI ion December 2004 to the date the ERP systemimplementation contract was signed between the government of the case study and the winning contractor in July 2009. This took more than 54 months compared to the 14 months estimated during the planning of the REPFMP. The pre-implementation phase of the ERP system was dominated by the procurement process. For this case study, the procurement phase can be viewed as three distinct periods: bid document preparation, first-stage bidding, and second-stage bidding.

Bid document preparation: The original plan was to allocate about 1 month to finalize the bidding document as the government had already prepared a preliminary set of functional and technical specifications for the information system to be procured before the loan was signed. At the end, it took 6 months. Even though the government managed to engage a consulting team to review, update, and finalize the bid document soon after loan signing, the resulting document lacked government ownership as the consulting team worked primarily on their own with minimal consultation with the stakeholders (Interviewees 1 and 8). One of the interviewees (Interviewee 3) stated that at the time there was no government structure to allow for dedicated staff to work alongside with the consultants to prepare the bid document. As a result, the technical knowledge embedded in the bid document did not flow directly, quickly, nor powerfully to those needed to fulfil the procurement process. This bid document was released to the public in September 2005 that started the firststage bidding of the procurement process.

First-stage bidding: The planned 7-month firststage bidding process turned into a 26 -month one. The 
two-stage ICT procurement process was a new approach the IFI rolled out in 2004 along with the release of a sample bid document that included a sample contract (Interviewee 6). The first stage focuses on determining the best qualified solutions submitted, leaving the evaluation of the cost proposals for the second stage. The objective is to ensure the best solution is chosen without the price-tags to tempt corrupt practices during procurement by the borrowing governments, a concern of the IFI. However, the two-stage ICT procurement process was an innovation without any success story recorded at the time when the loan for the REPFMP project was signed (Interviewees 6 and 12). One of the interviewees (Interviewee 6) suggested that the REPFMP was a test case for the IFI.

The request for proposals for the ERP procurement was released in September 2005. Four submitted proposals in November 2005. Prior to the bid evaluation, the government-hired independent verification and validation (IVV) team developed an evaluation framework for both the IVV and government teams to follow to ensure consistency in the evaluation approach and criteria used. The IVV team started the bid evaluation immediately and completed the evaluation by January 2006 (Interviewee 4). It took over two months for the government to reconcile its report with that of the IVV one (Interviewee 4). The entire contents of the evaluation report, including the contract and names of qualified bidders to proceed to the second stage of the bidding process required a formal no-objection response from the IFI. The IFI responded in May 2006. This marked the beginning of a series of revisions, and clarifications between the government and the IFI on contents and conclusions in the evaluation report that lasted till October 2007, when the second-stage bid document was distributed to the three qualified bidders to proceed to the second stage of the bidding process (based on reports and archival records). It took 15 months for the government and the IFI to agree on whether or not to disqualify some of the bidders. The government team insisted that only one bidder was qualified to proceed to the second stage. Both the IVV and the IFI teams independently considered there was more than one qualified bidder (Interviewees 4 and 6 , and archival records).

It was during these exchanges when an anonymous letter was sent to the president of the IFI at its headquarters complaining of nepotism practiced by the government project team (archival records). The finance minister responded by calling for an independent evaluation of the IFI's handling of the procurement process after all the senior officials declared that there had been no wrong-doing from their part (Interviewee 10). The IFI obliged by engaging a third party to conduct an investigation in the form of a desk review of all relevant documents related to the bidding process to date. The investigation took about 4 months resulting in a report stating that the IFI had handled the procurement process properly. The IFI issued its no-objection to proceed to the second-stage procurement process in February 2007 with a list of comments to be addressed by the government, which were completed in September 2007 after the investigation report was released. Three out of four bidders advanced to the second stage.

This segment of the procurement knowledge-flow loop almost did not complete. While the project team had adequate intrinsic need knowledge to execute the procurement process, and extrinsic need knowledge was available, residing with the vendor stakeholder group represented by the IVV team, and was transferred to the government project team, the latter did not directly and quickly gain nor use the extrinsic need knowledge by their refusal to accept the view that more than one bidder was qualified. It took catalytic knowledge as created by the minister's calling for an independent evaluation of the procurement process to finally complete the knowledge-flow loop.

Second-stage bidding: Given the second-stage bids were primarily on the financial aspect, the bidders were given 6 weeks to submit their proposals with the bid opening date set for late November 2007. Only two bids were submitted, but the bid opening date was changed multiple times. The actual opening date was in April 2008. One reason for the delay was the minister decided that a complete review of the FMIS project was needed to reevaluate whether the perceived benefits of an ERP system were still relevant to the finance ministry. The review of the relevance of the FMIS also served to build ownership among the rank and file (Interviewees 5, 7, and 9). The minister assigned one of the minister's special advisors to conduct this internal review during the first quarter of 2008. This special advisor was chosen to conduct the review because the advisor just returned from a multiyear assignment overseas, and was never involved in the design or preparation of the REPFMP, and, most importantly, the special advisor was highly regarded to be impartial. By the time the bid opening took place in April 2008, the review was submitted to the minister reaffirming the relevance of the FMIS system. It was, however, still 15 months away till the implementation contract was signed to mark the completion of the pre-implementation phase of the FMIS project.

Both bids were rejected immediately on the bid opening date citing non-compliance. All agreed that 
both bidders made significant mistake (Interviewees 5 and 6). The decision then was how best to continue without starting the entire procurement process from the beginning again. By this time, the project team had the requisite need knowledge, in all three aspects, to complete the procurement knowledge-flow loop. The government project team had at last gained intrinsic and acquired sufficient extrinsic knowledge, and catalytic knowledge was transferred explicitly, directly, and powerfully from both the top management and organization stakeholder groups that the FMIS system was critical and remained relevant to the ministry and the acquisition of it must proceed quickly.

The government project team proposed a "re-do" of the second-stage, which presented an opportunity to update the more than three-year-old bid document and to include requirements from the directorate-general of budget, a unit that had been resistant in participating in the project until now (Interviewees 2, 5, and 6). The delay in the procurement process and the minister's strong handling of the impasses encountered during the course of the procurement process afforded the time for others in the ministry to develop the absorptive capacity needed to gain the knowledge and to embrace the FMIS project (Interviewees 2 and 5). It also demonstrated the interrelationship between the three aspects of need knowledge, that all three were required to complete the knowledge-flow loop, and absence of even one aspect would obstruct the flow.

The revised bid document was sent to the three qualified bidders in August 2008 and bid opening was set for October 2008. The bid evaluation report prepared by the government team, with inputs from the IVV team, was submitted to the IFI in February 2009 after site visits to a local client of the lowest-priced bidder for the government team to observe and to gain additional extrinsic knowledge from peers' practical experience of implementing an information system. In May 2009, the IFI issued its no-objection after three rounds of clarification requests. The finance minister approved the winning bidder in June 2009 and the contract was signed in July 2009.

\subsection{The stakeholders}

Interviews of the stakeholder groups presented the third source of evidence on "why it happened" for this case study. Based on Nour and Mouakket's (2011) CSF framework for ERP implementation, organization and vendor stakeholder groups took on the role of consultation, information-system department the role of support, project team the role of fulfilment, and top management the role of authorization. The overarching guiding question posed during the interviews was to encourage the interviewees to describe their overall individual experience, which was contextualized by interrelated open-ended questions covering main counterparts, knowledge-sharing practices, key stumbling blocks, and doing differently in the future.

The overall experiences across the five stakeholder groups were negative as evidenced in the almost 5-year meandering need knowledge-flow loops. For example, the project team stakeholder group, particularly the government team, did not receive all three aspects of the need knowledge quickly, directly, and powerfully: insufficient and inefficient procurement training hindered intrinsic need knowledge acquisition and application; not accepting vendor group's information system-related recommendations during bid evaluation essentially rejected extrinsic need knowledge gain; and the delayed assertion of top management's authorization to proceed prolonged the uptake of catalytic need knowledge. the result was a protracted completion of the need knowledge-flow loop. While the project was complex and over-designed as described by some of the interviewees, stakeholders did not seem to be willing or able to join forces. The insertion of the minister's special advisors changed the dynamics of the working relationships across the stakeholder groups, especially the government ones (Interviewee 10). Within the project team, there need to be a technical specialist with hands-on experience in information system development to review the functional and technical requirements and to provide quality assurance support on system design and the bid documents (extrinsic need knowledge). Across the organization, staff need to be convinced that the system is important to them and it is important to appoint a reform-minded champion (catalytic need knowledge). A number of interviewees representing multiple stakeholder groups underscored that change management should be in place at the outset of the project. There should be dedicated resources with team members who have no other duties than those related to the project. Given that there was a lack of ownership with the bid document as it was developed by consultants with minimal discussions with the government teams, some interviewees considered that it would have been better for the government project team to have spent time upfront in developing the ERP system themselves to better understand the bid document itself (intrinsic need knowledge).

\section{Conclusions and summary}

Knowledge is a sustainable advantage and knowledge assets increase their value with use. This 
snowball effect of knowledge advantage advocates effective KM to foster its continual growth as it flows. Knowledge, however, flows unevenly throughout an organization and the problem is that the fundamental dynamics of these flows are still not well characterized in theoretical and computational models. This case study demonstrates an application of Nissen's multidimensional knowledge-flow model to explain how need knowledge flows across different stakeholders in an organization over time. This case study suggests there are three determinants for need knowledge, and further provides insights into the Nissen's [20] five knowledge-flow principles:

1. The first principle relates to the innate inertia of knowledge. Knowledge at rest remains at rest and knowledge in motion stays in motion, not unlike Newtonian physics. In the context of organizational knowledge flow, if a person or organization desires knowledge flow, then an actor must take some action to induce the flow, such as through formal or on-the-job training. However, if a person or organization requires restricted knowledge flow, then an actor must take some action to limit the flow. The actor in this case was the minister, representing the organization stakeholder group, whose catalytic need knowledge was instrumental in completing the knowledge-flow loop.

2. The second principle addresses the interactions between knowledge flows and organizational workflow processes. The second principle states that experiential processes (the doing) contribute to workflow processes, and educational processes (the learning) contribute to knowledge flows. It then follows that if the aim is to promote knowledge flows, it is important to understand how the specific need knowledge flows relate to organizational workflows; thus, changes to workflows would require changes to knowledge flows, and vice versa. The no-objection issuance process was the trigger in the reversal of the knowledge-workflow processes. The government team initiated a request by submitting a bid evaluation report and the IFI project team reviewed and issued a no-objection. These backand-forth iterations are obstructions to completing the procurement knowledge-flow loop.

3. The third principle furthers the concept of the relationship between knowledge flows and workflows. Workflows represent organizational processes. Knowledge-based actions or activities are associated with organizational processes that are responsible for the knowledge-flow phenomena. Knowledge flows therefore should always lie along the critical paths of workflows to enhance organizational performance. There was a collapse along the critical paths of the organizational processes throughout the procurement process evidenced from insufficient and inefficient procurement training (intrinsic knowledge), to refusal to gain ERP-related knowledge (extrinsic knowledge), to delayed provision of the authorizing environment (catalytic knowledge) as part of the ERP acquisition procurement process.

4. The fourth principle brings in the temporal dimension and states that knowledge flows and workflows operate on different time horizons; therefore, most knowledge flows need to complete their course before critical and dependent workflows can begin. The case study, through its numerous knowledge-workflow tributaries, provides a real-life model of this principle. The almost 2-year delay in the secondstage procurement process afforded the time horizon for a critical mass of government officials to reach the absorptive capacity to join up with the project by explicating their needs to be included in the eventual FMIS system.

5. The fifth knowledge-flow principle encapsulates the concept of knowledge power: explicit knowledge flows quickly and broadly but with relatively diluted power, whereas tacit knowledge flows comparatively slowly and narrowly but at higher power. In this case study, explicit knowledge carried the highest and strongest power throughout. The successful completion of the procurement process relied much on the minister explicitly issuing the need to proceed. The catalytic knowledge was instrumental in completing the procurement knowledge-flow loop.

This case study builds on existing workknowledge-flow theory, need-knowledge generation, and the critical success factors for ERP implementation - to examine the multidimensional knowledge-flow phenomenon in context. Future work could include:

- Expanding on the interactions among the five stakeholder groups and their evolving roles during the pre-implementation phase;

- Exploring the role of wisdom as described by Nguyen and Kohda [16] in judgement during the procurement evaluation process; and

- Applying Kaiser's [8] theory wave to learn from the envisioned future as the prerequisite for any major enterprise-wide system implementation.

\section{References}


[1] J. Dawson and J. Owens, "Critical success factors in the chartering phase: A case study of an ERP implementation", International Journal of Enterprise Information Systems, vol. 4, no. 3, 2008, pp. 9-24.

[2] C. Dener, J.A. Watkins, and W.L. Dorotinsky, Financial management information systems: 25 years of World Bank experience on what works and what doesn't, The World Bank, Washington, DC, 2011.

[3] Y. Guo, Y. Feng, and C. Wang, "The impact mechanism of organizational culture on ERP assimilation: A multi-case study", in $47^{\text {th }}$ Hawaii International Conference on System Science Proceedings, 2014, pp. 4044-4053, Institute of Electrical and Electronics Engineers Computer Society, Los Alamitos, CA.

[4] B. Hanisch, F. Lindner, A. Mueller, and A. Wald, "Knowledge management in project environments", Journal of Knowledge Management, vol. 13, no. 4, 2009, pp. 148160.

[5] M.E. Jennex, "Impacts from using knowledge: A longitudinal study from a nuclear power plant", International Journal of Knowledge Management, vol. 4, 2008, pp. 51-64. [6] M.C. Jones, M. Cline, and S. Ryan, "Exploring knowledge sharing in ERP implementation: An organizational culture framework", Decision Support Systems, vol. 41, 2006, pp. 411-434.

[7] A. Kaiser, B. Fordinal, and F. Kragulj, "Creation of need knowledge in organizations: An abductive framework", in $4^{\text {th }}$ Hawaii International Conference on System Science Proceedings, 2014, pp. 3499-3508, Institute of Electrical and Electronics Engineers Computer Society, Los Alamitos, CA.

[8] A. Kaiser, "Towards a knowledge-based theory of developing sustainable visions: The theory wave", in $50^{\text {th }}$ Hawaii International Conference on System Science Proceedings, 2017, pp. 4496-4504, Institute of Electrical and Electronics Engineers Computer Society, Los Alamitos, CA.

[9] Y. Kim, Y.S. Hau, S. Song, and G. Ghim, “Trailing organizational knowledge paths through social network lens: Integrating the multiple industry cases", Journal of Knowledge Management, vol. 18, 2013, pp. 38-51.

[10] C. Lin, J. Wu, and H. Tsai, "A hybrid approach to knowledge flow", Industrial Management \& Data Systems, vol. 113, 2013, pp. 628-646.

[11] P. Liu, "Empirical study on influence of critical success factors on ERP knowledge management on management performance in high-tech industries in Taiwan", Expert Systems with Applications, vol. 38, 2011, pp. 10696-10704. [12] S. Macmillan, J. Steel, S. Austin, P. Kirby, and R. Spence, R. "Development and verification of a generic framework for conceptual design", Design Studies, vol. 22, 2001, pp. 169-191.

[13] T.C. McGinnis and Z. Huang, "Rethinking ERP success: A new perspective from knowledge management and continuous improvement", Information \& Management, vol. 44, 2007, pp. 626-634.

[14] F.F-H. Nah, J.L-S. Lau, and J. Kuang, "Critical factors for successful implementation of enterprise systems", Business Process Management Journal, vol. 7, 2001, pp. 285-296.
[15] T. Negi, and V. Bansal, "A methodology to bridge information gap in ERP implementation life cycle", International Journal of Enterprise Information Systems, vol. 9, no. 2, 2013, pp. 70-82.

[16] L. Nguyen, and Y. Kohda, "Toward a model of wisdom determinants in the auditing profession", in $50^{\text {th }}$ Hawaii International Conference on System Science Proceedings, 2017, pp. 4604-4613, Institute of Electrical and Electronics Engineers Computer Society, Los Alamitos, CA.

[17] M.E. Nissen, "An extended model of knowledge-flow dynamics", Communications of the Association for Information Systems, vol. 8, 2002, pp. 251-266.

[18] M.E. Nissen, "Dynamic knowledge patterns to inform design: A field study of knowledge stocks and flows in an extreme organization", Journal of Management Information Systems, vol. 22, no. 3, 2006, pp. 225-263.

[19] M.E. Nissen, Harnessing knowledge dynamics: Principled organizational knowledge and learning, IRM Press, Hershey, PA, 2006.

[20] M.E. Nissen, Harnessing dynamic knowledge principles in the technology-driven world, IRM Press, Hershey, PA, 2014.

[21] I. Nonaka, R. Toyama, and N. Konno, "SECI, $B a$ and leadership: A unified model of dynamic knowledge creation" Long Range Planning, vol. 33, 2000, pp. 5-34.

[22] M.A. Nour and S. Mouakket, "A classification framework of critical success factors for ERP systems implementation: A multi-stakeholder perspective", International Journal of Enterprise Information Systems, vol. 7, no. 1, 2011, pp. 56-71.

[23] D.E. O'Leary, "Knowledge management across the enterprise resource planning systems life cycle", International Journal of Accounting Information Systems, vol. 3, 2002, pp. 99-110.

[24] R. Palanisamy, "Organizational culture and knowledge management in ERP implementation: An empirical study", The Journal of Computer Information Systems, vol. 48, no. 2, 2008, pp. 100-120.

[25] P. Poon and Y.T. Yu, "Investigating ERP systems procurement practice: Hong Kong and Australian experiences", Information and Software Technology, vol. 52, 2010, pp. 1011-1022.

[26] Z. Pourzolfaghar, Z., R. Ibrahim, R. Abdullah, N.M. Adam, and A.A.A. Ali, "Improving dynamic knowledge movements with a knowledge-based framework during conceptual design of a green building project", International Journal of Knowledge Management, vol. 9, 2013, pp. 62-79. [27] E. J. Umble, R. R. Haft, and M. M. Umble, "Enterprise resource planning: Implementation procedures and critical success factors", European Journal of Operational Research, vol. 146, 2003, pp. 241-257.

[28] R. Vandaie, "The role of organizational knowledge management in successful ERP implementation projects", Knowledge-Based Systems, vol. 21, 2008, pp. 920-926.

[29] E.T.G. Wang, C.C. Lin, J.J. Jiang, and G. Klein, "Improving enterprise resource planning (ERP) fit to organizational process through knowledge transfer", International Journal of Information Management, vol. 27, 2007, pp. 200-212.

[30] R.K. Yin, Case study research: Design and methods, 5th ed., Sage, Thousand Oaks, CA, 2014. 